$[15,16]$. Silver can be coated using immersion or electroless plating method and sono-electrochemical processes [16]. Immersion coating process proceeds by galvanic displacement reaction, but a significant disadvantage is that the as synthesized samples are not suitable for high temperature applications. Besides, the immersion coating process generates silver shell with thickness in the range of several nanometers $[17,18]$.

Bimetallic transition metal nanocatalysts are proven to be efficient in different catalytic reactions due to potential synergistic effects between components as well as easy engineering of size, shape, composition and stability [19]. In this context, effective designing of bimetallic nanocatalysts of copper and silver will be of particular interest. There are previous reports on the synthesis of $\mathrm{Cu}-\mathrm{Ag}$ alloyed nanostructures as potential catalysts for $p$-nitrophenol reduction; however, the proposed synthesis of $\mathrm{Cu}$-Ag alloyed bimetallic nanoparticles takes a long time, at least $7 \mathrm{~h}$ [10]. Coppersilver $(\mathrm{Cu}-\mathrm{Ag})$ mixed nanoparticles loaded on the surface of cellulose acetate and plant supported bimetallic $\mathrm{Cu}-\mathrm{Ag}$ have also been proven to be better nanocatalysts for the conversion of $p$-nitrophenol to $p$-aminophenol [7]. Prior research indicates that the catalytic efficiency of metal based nanocatalysts was significantly affected by the incorporation of metal oxide materials [20-22]. In 2017, Liang et al. and coworkers developed $\mathrm{Cu} / \mathrm{CuO}-\mathrm{Ag}$ composites and studied its efficiency on the removal of organic pollutants [23]. They carried out the synthesis by a two step process involving polyvinylpyrrolidone (PVP) and cetyl trimethyl ammonium bromide (CTAB). However, the reported method requires $12 \mathrm{~h}$ for the completion of the synthesis of the catalytic material. To the best of our knowledge, this is the only report demonstrating the synthesis of a nanocomposite consisting of Ag, $\mathrm{Cu}$ and $\mathrm{CuO}$. In this paper, we have developed a $\mathrm{Cu}-\mathrm{CuO}-\mathrm{Ag}$ nanocomposite with a simple chemical reduction method possessing significantly reduced reaction time. By varying the amount of metallic precursor, different compositions of the $\mathrm{Cu}-\mathrm{CuO}-\mathrm{Ag}$ nanocomposites were synthesized and their structural and morphological characterizations were carried out. Finally, the catalytic efficiency of the synthesized $\mathrm{Cu}-\mathrm{CuO}-\mathrm{Ag}$ nanocomposite was analyzed by taking the hydrogenation reduction of $p$-nitrophenol using $\mathrm{NaBH}_{4}$ as the model reaction. Furthermore, we have also optimized the catalyst amount required for the proposed reduction reaction.

\section{Materials and method}

\subsection{Materials used}

Cupric chloride (99\% LOBA Chemie, India), Silver nitrate ( 99.9\%, Emparta, Merck), Ethylene diamine (98\%, LOBA
Chemie, India), Hydrazine hydrate (80\%, Emparta, Merck, India), Sodium borohydride (95\%, Emparta, Merck, India), p-nitrophenol (4-NP) (98\%, HIMEDIA, India), and copper metal powder (99.5\%, SRL Chemicals, India) were used for the synthesis and characterization of material. All the chemicals were of analytical grade without further purification and all aqueous solutions were prepared with double distilled water.

\subsection{Synthesis of $\mathrm{Cu}-\mathrm{CuO}$ nanocomposite}

In a typical synthesis of $\mathrm{Cu}-\mathrm{CuO}$ nanocomposite, about $12 \mathrm{~mL}$ of $0.2 \mathrm{M} \mathrm{CuCl}_{2}$ solution was dissolved in $1.5 \mathrm{M}$ $\mathrm{NaOH}$ solution. To this $7.5 \mathrm{~mL}$ ethylene diamine (EDA) and $3 \mathrm{~mL}$ hydrazine hydrate (80\%) were added with continuous stirring. The mixed solution was heated to $80^{\circ} \mathrm{C}$ and maintained for $60 \mathrm{~min}$ without stirring. The prepared solid sample was separated by filtration and dried under IR lamp for $2 \mathrm{~h}$.

\subsection{Synthesis of $\mathrm{Ag} / \mathrm{Cu} / \mathrm{CuO}$ nanocomposite}

About $0.8978 \mathrm{~g} \mathrm{AgNO}_{3}$ was added to $10 \mathrm{~mL}$ ethylene diamine solution and allowed to dissolve for $30 \mathrm{~min}$ at $60^{\circ} \mathrm{C}$. The completely dissolved solution was then poured into $\mathrm{Cu}-\mathrm{CuO}$ nanocomposite dispersed in ethylene diamine in a three necked flask, which was then magnetically stirred for $2 \mathrm{~h}$ at $80^{\circ} \mathrm{C}$. The resulting solution was then centrifuged and washed several times with water and separated by several rounds of centrifugation. Similarly, we synthesized four different compositions of $\mathrm{Ag}-(\mathrm{Cu}-\mathrm{CuO})$ nanocomposites by varying the molar ratios of $\mathrm{Cu}$ and $\mathrm{Ag}$ precursors in the ratios 4:1, 8:1, 16:1 and 32:1. The amount of reducing agent and capping agent was kept constant for all synthesis. In the following text, the synthesized samples are designated as CA1, CA2, CA3 and CA4 respectively.

\subsection{Characterization}

X-ray diffractometer model D8 Advance (Bruker) with Cu Ka radiation $(\lambda=1.54178 \mathrm{~A})$ was used for $X$-ray diffraction (XRD) analysis at a scanning rate of $0.02^{\circ} \mathrm{s}^{-1}$ in the $2 \theta$ range from 20 to 80 . Surface morphologies and EDX analysis of the products were characterized using Hitachi SU8010 scanning electron microscope. UV-Vis spectrophotometer (UV-2550, Shimadzu, Japan) was used for the catalytic study. The high-resolution transmission electron microscope analysis of the samples was carried out using TALOS F200S G2STEM. 


\subsection{Catalytic reduction of $p$-nitrophenol}

The catalytic performances of the synthesized samples were analyzed using the aqueous phase hydrogenation of p-nitrophenol by sodium borohydride. In a typical catalytic study, $7.5 \mathrm{mg}$ of the prepared catalyst was dispersed in a $10 \mathrm{~mL}$ of aqueous $p$-nitrophenol solution $(1 \mathrm{mM})$ at room temperature. Then a freshly prepared aqueous solution of $\mathrm{NaBH}_{4}(3 \mathrm{~mL}, 0.04 \mathrm{M})$ was added as the reducing agent. $2 \mathrm{~mL}$ of the above solution was immediately transferred into a quartz cuvette, diluted with distilled water and the absorption spectra measured at regular intervals of time. The change in the absorption spectrum was monitored using a UV-Vis spectrophotometer.

\section{Results and discussion}

\subsection{Structural and morphological study}

We have synthesized $\mathrm{Cu}-\mathrm{CuO}-\mathrm{Ag}$ nanocomposite by a two-step chemical reduction method. In the first step, spherical $\mathrm{Cu}$ nanoparticles were synthesized using an aqueous chemical reduction method. The schematic diagram of the synthesis of $\mathrm{Cu}-\mathrm{CuO}-\mathrm{Ag}$ nanocomposites is shown in Fig. 1.

Hydrazine hydrate reduces the $\mathrm{Cu}^{2+}$ into metallic copper. Ethylene diamine controls the shape and size of the nanoparticles formed. Ethylene diamine also prevents the agglomeration of the nanoparticles by adsorbing on the (100) facet [24]. After synthesis, under the drying conditions, the surface of the resulting copper nanoparticles is oxidized to form a $\mathrm{Cu}-\mathrm{CuO}$ nanocomposite. In the second step, the copper nanoparticles in the nanocomposite get replaced by silver ions through transmetallation reaction. The galvanic replacement of single copper ions by two silver atoms follow the reaction
$\mathrm{Cu}+2 \mathrm{Ag}^{+} \rightarrow \mathrm{Cu}^{2+}+2 \mathrm{Ag}$

This equation suggests that the amount of precursor plays a crucial role in the composition of $\mathrm{Cu}-\mathrm{CuO}-\mathrm{Ag}$ nanocomposites. We prepared four different compositions of the nanocomposite by varying the atomic ratio of copper to silver precursor. Reports suggest that in the synthesis of nanocomposites, more often, the final product will not be consistent with the feeding molar/atomic ratio due to the incomplete diffusion of second metal into the initially formed primary structure. Several factors such as reaction temperature and reaction time influence the surface diffusion process [25]. In the present study, silver is first converted to a silver-amine complex prior to addition to $\mathrm{Cu}-\mathrm{CuO}$ nanoparticles. The $\mathrm{X}$-ray crystallographic patterns of the synthesized $\mathrm{Cu}-\mathrm{CuO}$ and $\mathrm{Cu}-\mathrm{CuO}-\mathrm{Ag}$ nanocomposites are shown in Fig. 2.

The sharp peaks in the XRD patterns suggest the crystalline nature of the synthesized nanocomposites. The XRD pattern of $\mathrm{Cu}-\mathrm{CuO}$ nanocomposites shows crystalline peaks at 2 theta $43.56^{\circ}, 50.8^{\circ}$ and $74.68^{\circ}$ corresponding to the (111), (200) and (220) planes of metallic copper (JCPDS 04-0836). The peaks at $35.63^{\circ}, 38.71^{\circ}, 49.01^{\circ}, 58.25^{\circ}, 61.70^{\circ}$, $66.21^{\circ}, 68.08^{\circ}$ indicate the (002), (111), (200), (202), (113), (311), (220) planes of monoclinic CuO (JCPDS 48-1548). The XRD pattern of all the $\mathrm{Cu}-\mathrm{CuO}-\mathrm{Ag}$ nanocomposites contains peaks at $38.31^{\circ}, 44.28^{\circ}, 64.52^{\circ}$ and $77.43^{\circ}$ corresponding to peaks of (111), (200), (220) and (311) phases of metallic silver (JCPDS 04-0783).

It can be found that all the $\mathrm{Cu}-\mathrm{CuO}-\mathrm{Ag}$ nanocomposites except $\mathrm{CA} 1$ shows XRD patterns corresponding to metallic copper and monoclinic copper oxide. The sample CA1 contains only peaks corresponding to monoclinic copper oxide and metallic silver. The absence of peaks of metallic copper can be due to the higher concentration of silver nitrate in the precursor solution. Based on previous reports, the increase in intensity of the $\mathrm{Ag}(111)$ peak is

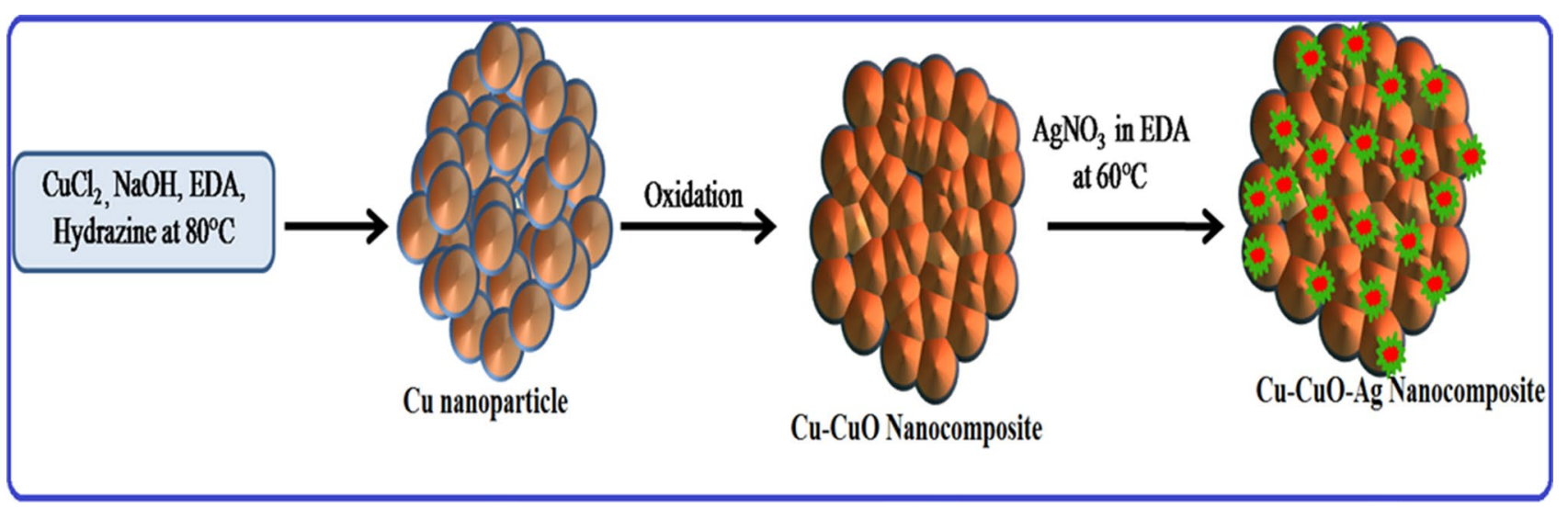

Fig. 1 Schematic diagram of the formation of $\mathrm{Cu}-\mathrm{CuO}-\mathrm{Ag}$ nanocomposite 
Fig. 2 XRD patterns of a $\mathrm{Cu}-\mathrm{CuO}$ and $\mathrm{Cu}-\mathrm{CuO}-\mathrm{Ag}$ nanocomposites, b CA1, c CA2, d CA3 and e CA4 respectively

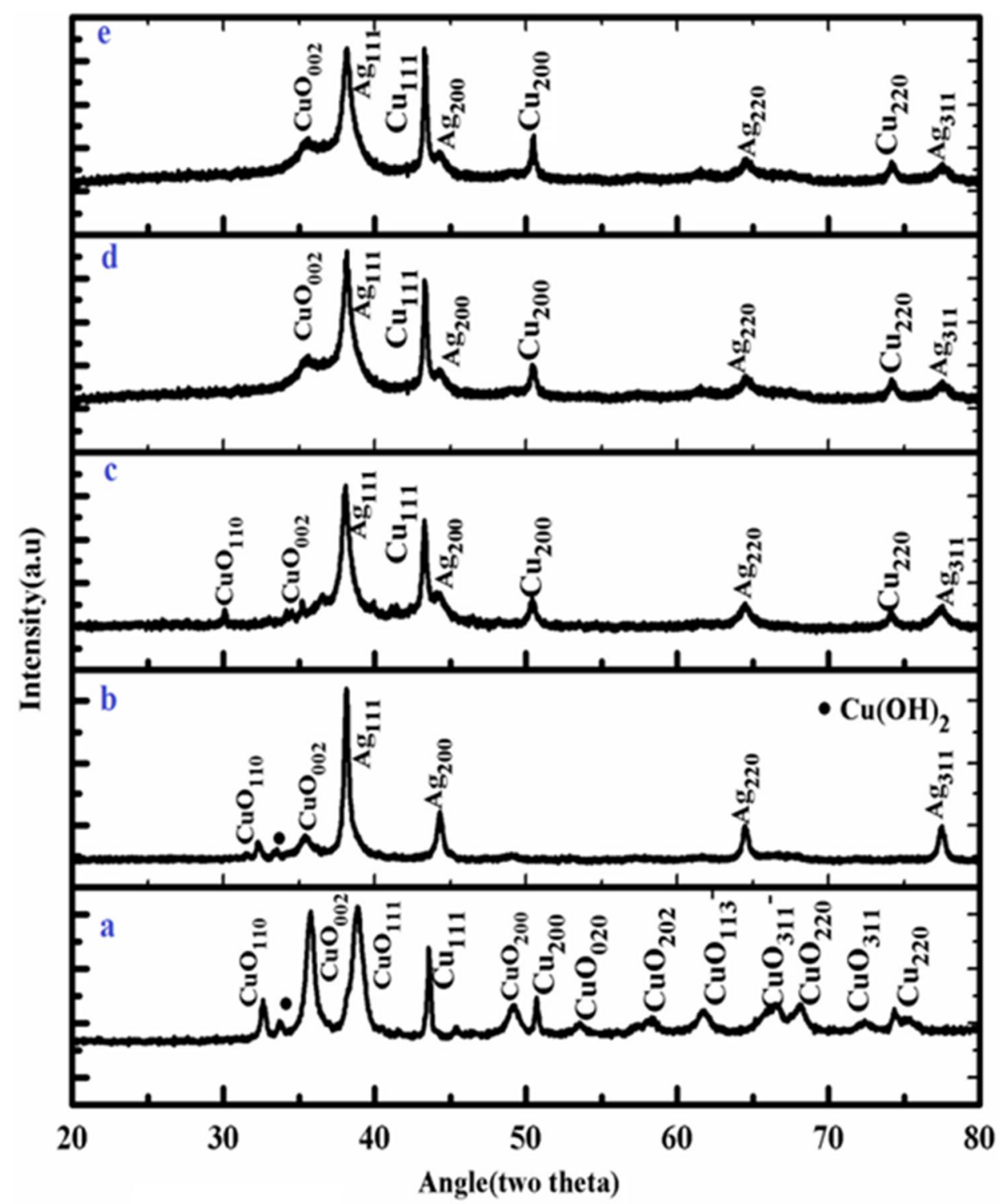

proportional to the amount of $\mathrm{Ag}$ in the sample, and the increase in sharpness of Ag (200) peak is proportional to the crystallinity of the $\mathrm{Ag}$ component. The highly intense peaks of $\mathrm{Ag}(111)$ at $38.31^{\circ}$ in the sample CA1 indicates the higher amount of free silver in the sample due to dewetting process. The silver dewetting causes more fraction of elemental copper in the initially prepared $\mathrm{Cu}-\mathrm{CuO}$ nanocomposite to get exposed to atmospheric oxygen resulting in its oxidation to form $\mathrm{CuO}$ and may be the reason for the absence of metallic copper in the CA1 sample [16]. From the XRD patterns it is clear that, in the synthesized $\mathrm{Cu}-\mathrm{CuO}-\mathrm{Ag}$ nanocomposites, the peak position of the $\mathrm{Ag}, \mathrm{Cu}$ and $\mathrm{CuO}$ phases retains its position as in their standard JCPDS cards. This confirms the fact that the samples formed were composites and not alloys. The broadening of the $\mathrm{Ag}$ (200) peaks observed as we move from sample CA1 to sample CA4 can be attributed to the Ag dewetting process [16]. Besides, the $\mathrm{Cu}-\mathrm{CuO}$ and CA1 sample contains a single peak at $33.62^{\circ}$ corresponding to the (002) plane of $\mathrm{Cu}(\mathrm{OH})_{2}$ (JCPDS 35-0505). It may be formed from the hydroxylation of the synthesized copper nanoparticles. The decrease in atomic weight percentage of silver makes the $\mathrm{Cu}, \mathrm{CuO}$ and $\mathrm{Ag}$ peaks more distinct. As evident from the XRD patterns an increase in the concentration of silver results in an increase in the intensity of the (111) peak of silver $\left(38.10^{\circ}\right)$ and a decrease in the reflection intensity of the metallic Cu (200) (43.56 ).

Figure 3 shows the SEM images of synthesized $\mathrm{Cu}-\mathrm{CuO}$ and $\mathrm{Cu}-\mathrm{CuO}-\mathrm{Ag}$ nanocomposites. The samples are spherical in shape and homogeneously distributed with some particle aggregation. The EDS analysis data is given in the supplementary data (figure S1). The percentage 
Table 1 Percentage composition of Copper, silver and oxygen present in the $\mathrm{Cu}-\mathrm{Ag}$ nanocomposites

\begin{tabular}{llll}
\hline Sample & Copper (\%) & Silver (\%) & Oxygen (\%) \\
\hline CA1 & 13.2 & 81.3 & 5.5 \\
CA2 & 14.6 & 73.1 & 12.30 \\
CA3 & 19.2 & 66.2 & 14.6 \\
CA4 & 54 & 9.0 & 37 \\
\hline
\end{tabular}

composition of $\mathrm{Cu}, \mathrm{Ag}$ and $\mathrm{O}$ present in the synthesized $\mathrm{Cu}-\mathrm{Ag}$ nano composites obtained from energy dispersive $\mathrm{X}$-ray spectroscopic analysis are shown in Table 1.

Figure 4 shows the TEM image of the as synthesized CA3 nanocomposite, which shows that the product consists of spherical nanocrystals. As shown in HRTEM image, three sets of lattice fringes at $0.236,0.203$ and $0.204 \mathrm{~nm}$ can be seen which can be indexed to the (111), (222) of $\mathrm{Ag}$ and (111) of Cu respectively.

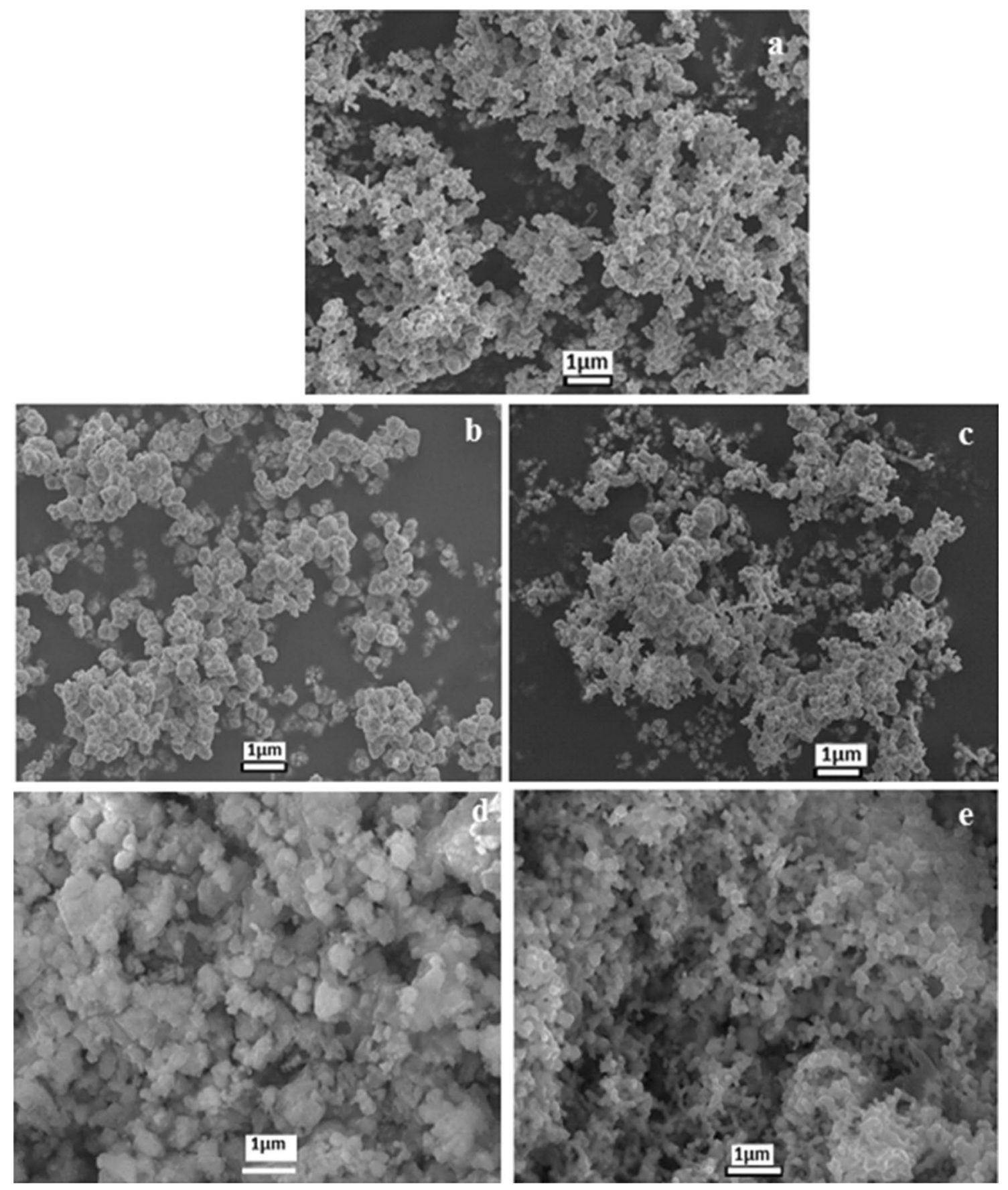

Fig. 3 SEM images of $\mathbf{a} \mathrm{Cu}-\mathrm{CuO}$ and $\mathrm{Cu}-\mathrm{CuO}-\mathrm{Ag}$ nanocomposites as $\mathbf{b} \mathrm{CA} 1, \mathbf{c} \mathrm{CA} 2, \mathbf{d} \mathrm{CA} 3$ and $\mathbf{e}$ CA4 respectively 


\subsection{Catalytic study-hydrogenation reduction of $p$-nitrophenol}

The catalytic hydrogenation of $p$-nitrophenol has been extensively studied by researchers since it is a suitable model reaction for analyzing the catalytic activity of most materials [20, 26-28]. Moreover, $p$-nitrophenol is a highly toxic organic pollutant which is difficult to degrade under normal conditions. The EPA drinking water guidelines limit the percentage of nitrophenols in drinking water to $0.06 \mathrm{ppm}$. It is well reported that in the absence of a catalyst, the strong reducing agent $\mathrm{NaBH}_{4}$ is not able to carry out the hydrogenation of $p$-nitrophenol (4-NP) $[29,30]$. The UV-Visible absorption peak of pure $p$-nitrophenol is at $317 \mathrm{~nm}$. The addition of $\mathrm{NaBH}_{4}$ to the aqueous reaction solution creates basic conditions resulting in the conversion of nitro phenol to nitrophenolate ions and then the absorption peak shifts to $400 \mathrm{~nm}$. But when $\mathrm{Cu}-\mathrm{CuO}-\mathrm{Ag}$ nanocomposites were added, the reduction of $p$-nitrophenol to $p$-aminophenol occurs within five minutes, and the conversion is indicated by the decrease in the absorption peak of nitrophenol at $400 \mathrm{~nm}$ with a simultaneous increase in the peak at $300 \mathrm{~nm}$ corresponding to $p$-aminophenol [30]. Also, there is visible change in the color of the solution from pale yellow to colorless. Since, in our study, the concentration of sodium borohydride was 40 times that of $p$-nitrophenol, the rate constant of the reaction can be analyzed by the pseudo-first order reaction kinetics. The rate constant values of the catalytic hydrogenation reaction performed were obtained from the plot of $\ln \mathrm{C} /$ $C_{0}$ versus time where $C / C_{0}$ is the relative intensity of concentration at $400 \mathrm{~nm}$. Figure 5 shows the UV Vis absorption plot of hydrogenation reduction of $p$-nitrophenol reduction using the commercial copper metal powder (Fig. 5a), synthesized $\mathrm{Cu}-\mathrm{CuO}$ (Fig. 5b) and $\mathrm{Cu}-\mathrm{CuO}-\mathrm{Ag}$ nanocomposites (Fig. 5c-f). The time taken for the reduction of $p$-nitrophenol in solution is noticeably less when we use $\mathrm{Cu}-\mathrm{CuO}-\mathrm{Ag}$ nanocomposites compared to commercial copper powder suggesting the improved catalytic efficiency of $\mathrm{Cu}-\mathrm{CuO}-\mathrm{Ag}$ nanocomposites. Among the $\mathrm{Cu}-\mathrm{CuO}-\mathrm{Ag}$ nanocomposites, $\mathrm{CA} 3$ nanocomposite reduces whole of the $p$-nitrophenol in solution within 4 min and shows the maximum catalytic efficiency.

The catalytic efficiency of the prepared samples were further established by comparing the activity of commercial copper powder under the same conditions and is shown in Fig. 5a. Figure 6 displays the correlation data between the rate of decrease in the peak at $400 \mathrm{~nm}$ with increasing time by monitoring the UV-Vis absorption spectrum ( $-\ln C / C_{0}$ Vs. time plot). The plot clearly demonstrates that the reaction is pseudo-first order. It is found that with $7.5 \mathrm{mg}$ of the catalysts, the apparent rate constant values obtained for commercial copper powder, $\mathrm{Cu}-\mathrm{CuO}$ nanocomposite, CA1, CA2, CA3 and CA4 nanocomposites were found to be $0.093,0.125,0.148$, $0.188,0.565$ and $0.432 \mathrm{~min}^{-1}$, respectively. It can be well understood that among $\mathrm{Cu}-\mathrm{CuO}$ and $\mathrm{Ag}-\mathrm{Cu}-\mathrm{CuO}$ nanocomposites, the maximum catalytic activity was shown by $\mathrm{CA} 3$ sample for the catalytic hydrogenation
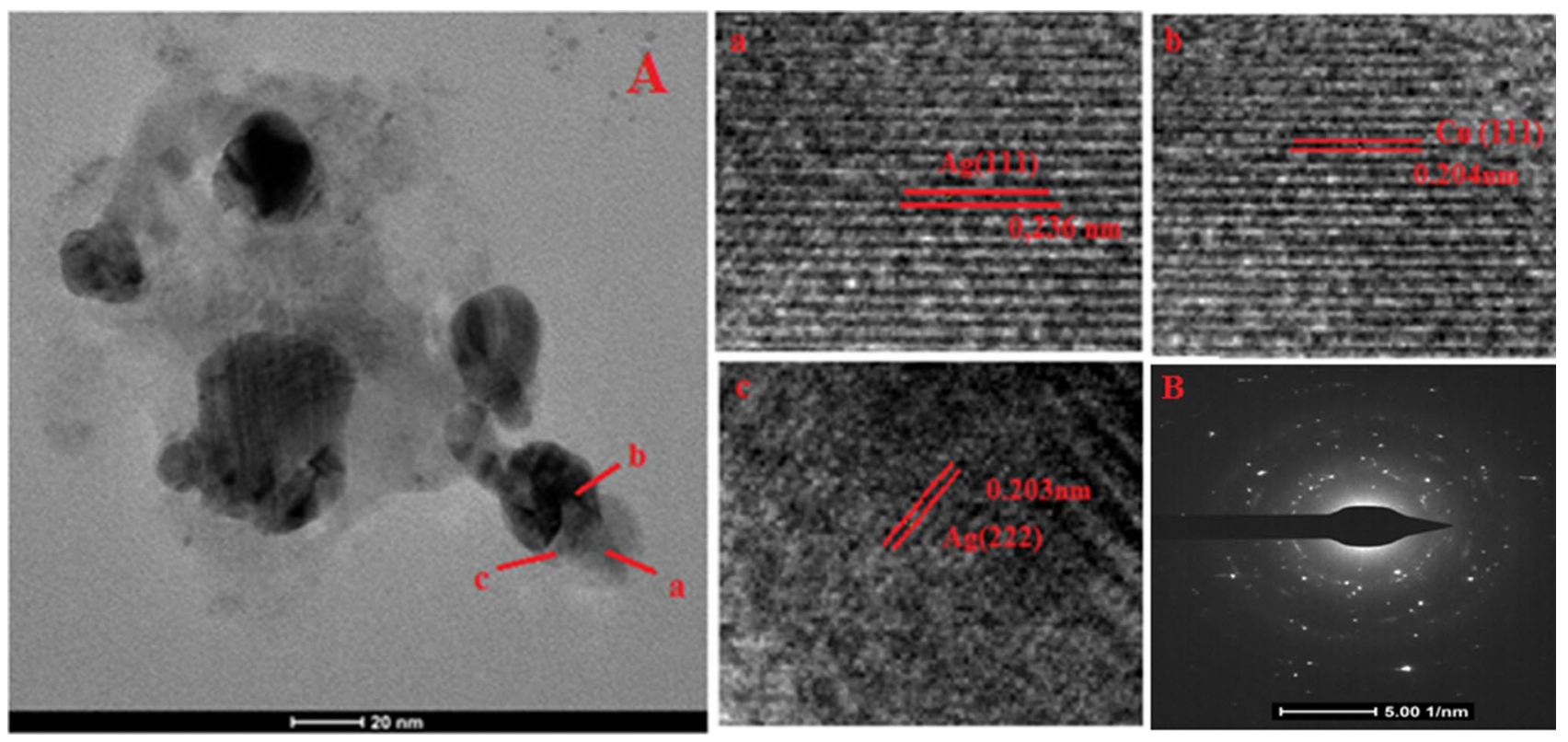

Fig. 4 A TEM image of CA3 nanocomposite and a, b and $\mathbf{c}$ show corresponding HRTEM image labeled as a, b and c area, respectively, B A selected area electron diffraction pattern of $\mathrm{Cu}-\mathrm{CuO}-\mathrm{Ag}$ nanocomposite 

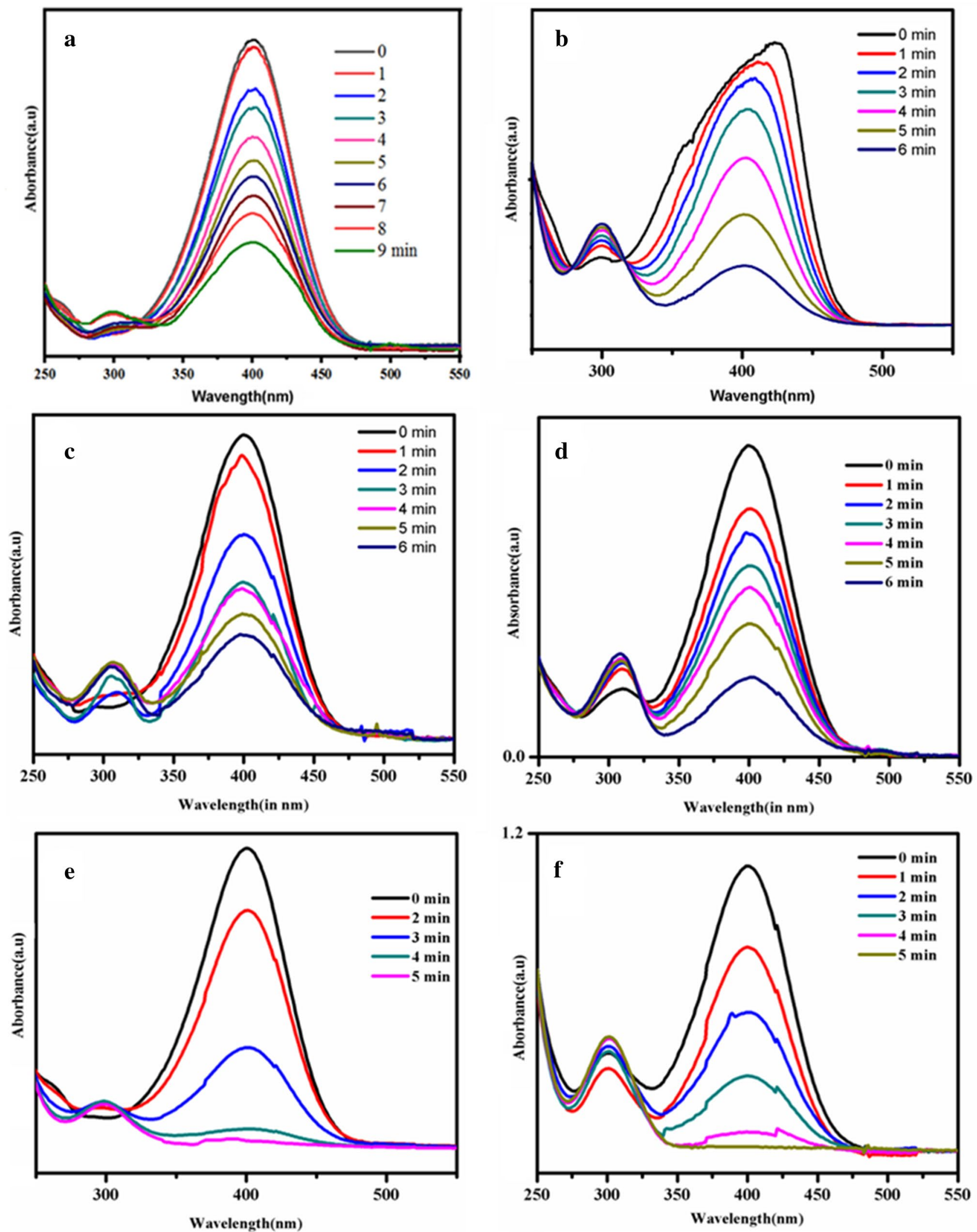

Fig. 5 UV absorption spectrum of hydrogenation reduction of $p$-nitrophenol using a commercial copper powder, $\mathbf{b}$ Cu-CuO nanocomposite, c CA1, $\mathbf{d}$ CA2, e CA3 and $\mathbf{f}$ CA4 respectively 


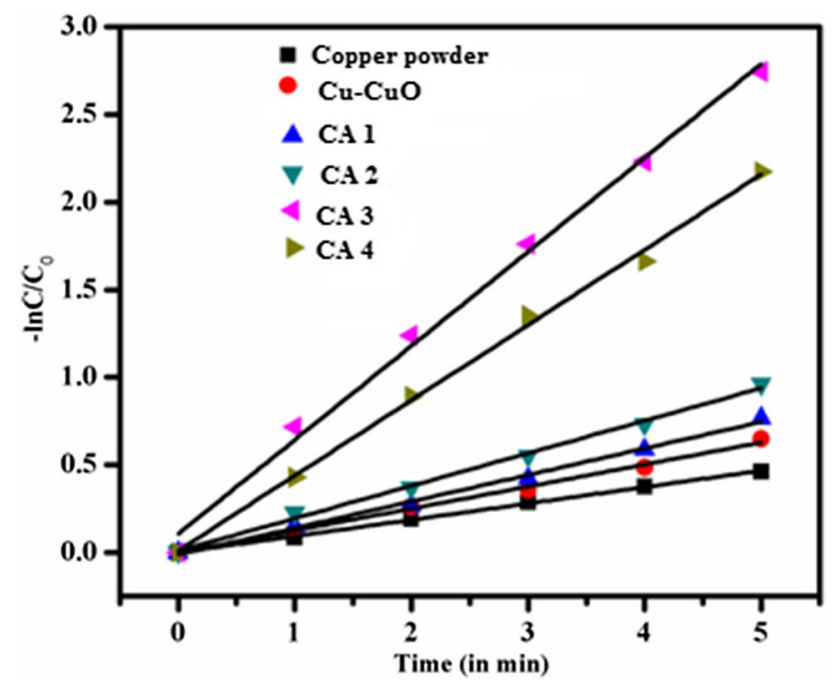

Fig.6 Plot of $-\mathrm{InC} / \mathrm{C}_{0}$ plot of commercial copper powder, $\mathrm{Cu}-\mathrm{CuO}$ nanocomposite and CA1, CA2, CA3, CA4 respectively

of $p$-nitrophenol to $p$-aminophenol, which is about 4.5 fold compared to that of $\mathrm{Cu}-\mathrm{CuO}$ nanocomposite.

Since the catalytic stability is an important factor that determines the efficiency of the catalyst, the recyclability of the catalyst was also monitored by carrying out four successive cycles of the catalytic hydrogenation using a definite amount of the prepared catalyst under the same experimental conditions. After each catalytic cycle, the separation of the catalyst from the reaction mixture is done by centrifugation followed by washing with distilled water several times and then used for the next cycle.

Figure 7 shows the relative rate plot of the recyclability result of hydrogenation reduction of $p$-nitrophenol with $\mathrm{NaBH}_{4}$ catalyzed by $\mathrm{Cu}-\mathrm{CuO}$ and $\mathrm{Ag}-\mathrm{Cu}-\mathrm{CuO}$ nanocomposites. It is clear that among the synthesized catalysts, the maximum recyclability was shown by $C A 3$ nanocatalysts without any significant decrease in the catalytic efficiency even after four cycles of the hydrogenation reduction of $p$-nitrophenol and indicates the noticeable stability of the catalyst compared to all other samples. From the catalytic data, it is well understood that CA3 nanocrystals were efficient catalyst for hydrogenation reduction of p-nitrophenol.

The XRD patterns of the used catalyst after four cycles of the catalytic reduction reaction are shown in Fig. 8 . For $\mathrm{Cu}-\mathrm{CuO}$ nanocomposite, there are only peaks corresponding to monoclinic copper oxide after four cycles of the catalytic reduction reaction indicating the lower stability of the copper nanocrystals. However, a single peak at $33.6^{\circ}(2 \theta)$ corresponding to $\mathrm{Cu}(\mathrm{OH})_{2}$ remains in this sample. However, for CA1, CA2 and CA3 nanocrystals, there is no change in the XRD patterns even after four cycles of the catalytic runs. In CA4, the peaks corresponding to

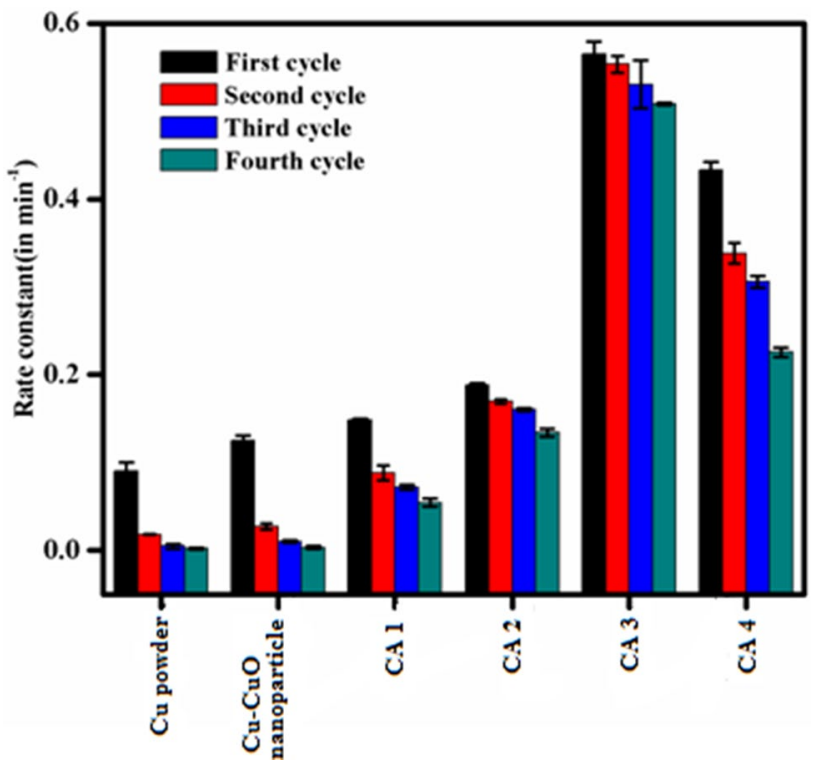

Fig. 7 Plot of recyclability of various catalysts for four cycles of the hydrogenation reduction of $p$-nitrophenol

monoclinic $\mathrm{CuO}$ at $2 \theta$ angles $32.4^{\circ}, 35.6^{\circ}$ and $38.3^{\circ}$ are present in minute amounts. However, for all the $\mathrm{Cu}-\mathrm{CuO}-\mathrm{Ag}$ nanocatalysts, the peaks corresponding to metallic silver becomes prominent indicating the successful conversion of metallic $\mathrm{Ag}(0)$ to $\mathrm{Ag}^{+}$and back to metallic silver after catalytic reduction reaction. There is no presence of silver oxide. The higher and stable catalytic performance of the CA3 nanocrystals even after four catalytic runs indicates the stability of the nanocatalyst. However, CA2 shows a decreased catalytic performance even though its XRD patterns remain unchanged during catalytic cycles. Moreover, the decrease in apparent rate constant value for hydrogenation reduction of nitrophenol with every catalytic run may be due to the surface contamination of the sample after each catalytic cycle. At the same time, the higher stability of the CA4 nanocatalysts may be due to the more proper synergistic electronic interaction of constituent particles of the catalyst and proper interaction between the active sites with the nitrophenolate ions. This suggests that compositional effects are a crucial factor in determining the catalytic performance of these types of catalysts [30].

In order to optimize the amount of CA3 nanocatalyst required for the $p$-nitrophenol reduction reaction, we carried out the hydrogenation reaction with different amount of the catalyst. Kinetic plot (- $\mathrm{InC} / \mathrm{C}_{0} \mathrm{Vs}$ time) of the reduction reaction and relative rate plot of the apparent rate constant values of the hydrogenation reduction of $p$-nitrophenol in the presence of different amount of CA3 nanocrystals were given in Figs. 9 and 10 respectively. It can be observed that initially there is an increase in the 

nanocomposite, CA1, CA2, CA3 and $C A 4$ respectively after four cycles of catalytic reduction
Fig. 8 XRD pattern of $\mathrm{Cu}-\mathrm{CuO}$

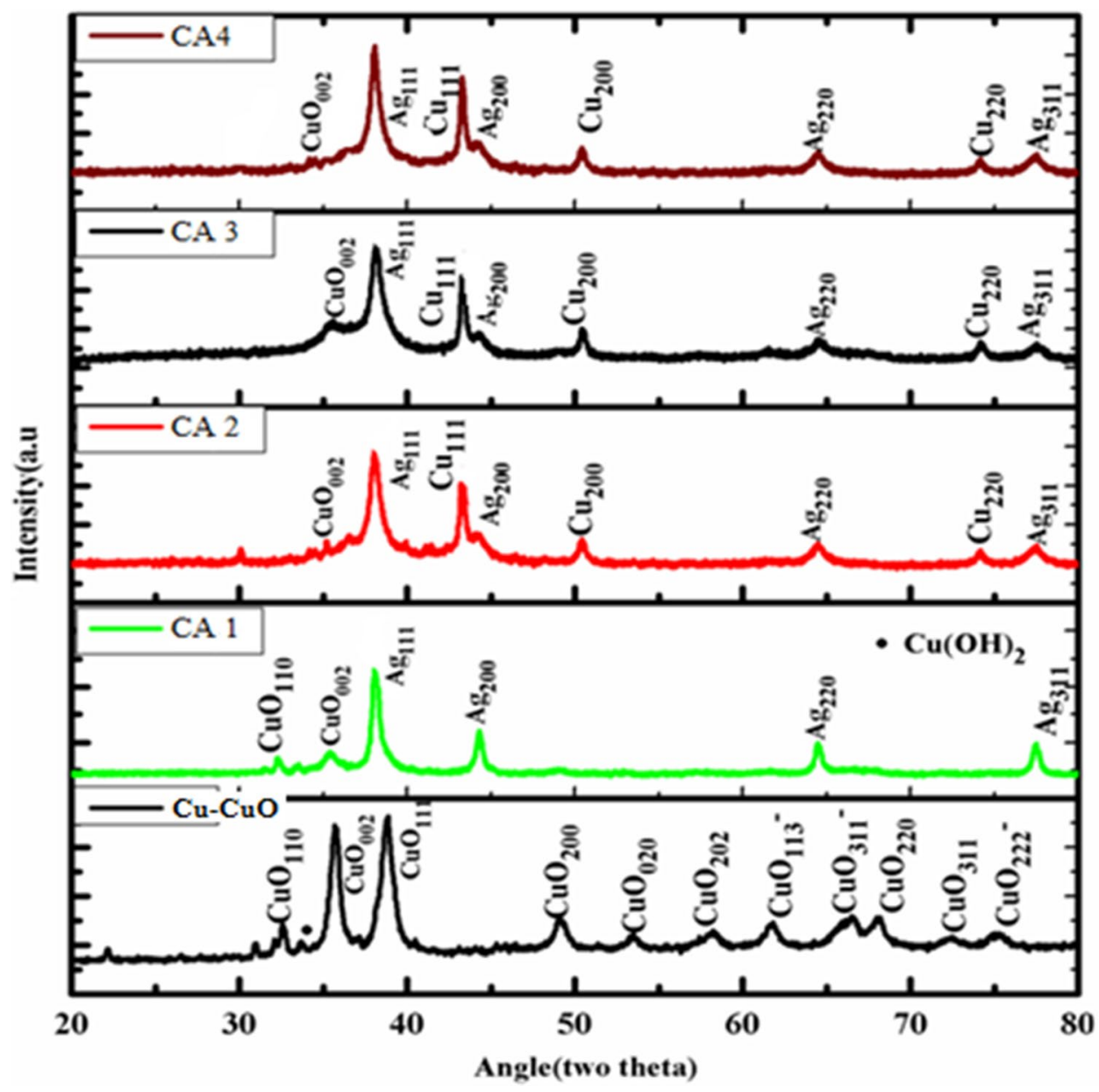

rate of the reaction on moving from $2.5 \mathrm{mg}$ to $10 \mathrm{mg}$ of the catalyst with a simultaneous increase in the rate from 0.079 to $0.632 \mathrm{~min}^{-1}$. The UV absorption plot suggests that using $2.5 \mathrm{mg}$ of the CA3 catalyst, reaction does not complete even after $14 \mathrm{~min}$ of the commencement of the reaction. With further increase in the amount of the catalyst from 10 to $12 \mathrm{mg}$, the time required for completion of the reaction remains $4 \mathrm{~min}$ while the apparent rate constant value decreases from 0.623 to $0.557 \mathrm{~min}^{-1}$. Thus, we have concluded that $10 \mathrm{mg}$ of the CA3 nano catalyst is optimum for the complete conversion of $p$-nitrophenol to $p$-aminophenol with a maximum rate constant value. The kinetic plot with a correlation coefficient value close to unity further confirms the pseudo-first order kinetics for the reaction [31].

Since most of the as synthesized $\mathrm{Cu}-\mathrm{CuO}$ and $\mathrm{Cu}-\mathrm{CuO}-\mathrm{Ag}$ nanocomposite were of almost identical shape, it can be concluded that particle size of the catalyst is not the mere reason for the varying catalytic activity. The increase in catalytic reduction rate with increasing catalyst amount can be attributed to the increase in the amount of catalytically active sites available for the reduction reaction. The incorporation of silver into $\mathrm{Cu}-\mathrm{CuO}$

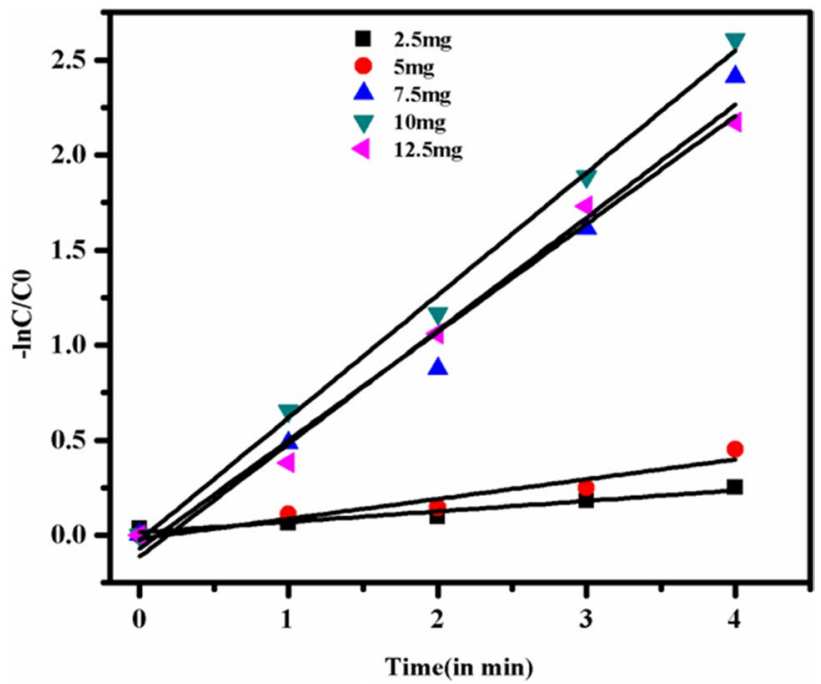

Fig. 9 Kinetic plot (-In $C / C_{0}$ Vs time) of the reduction reaction in the presence of different amount of CA3 nanocrystals

nanocomposite increases the catalytic activity of the samples indicating the importance of silver in the proposed catalytic reaction. The decrease in reduction rate with 


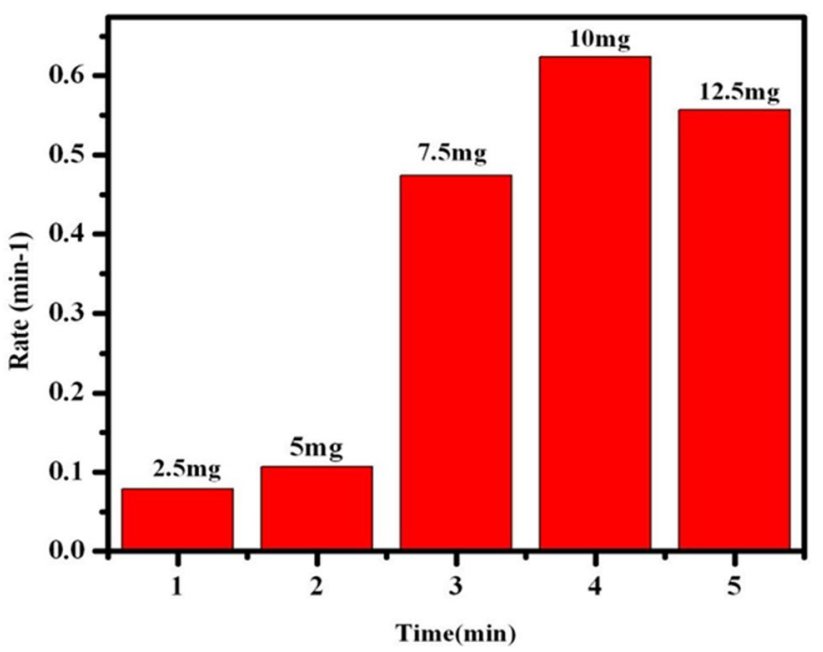

Fig. 10 Relative rate plot of the apparent rate constant values of the hydrogenation reduction of $p$-nitrophenol in the presence of different amount of CA3 nanocrystals

further increase in the amount of the catalyst to $12.5 \mathrm{mg}$ may be due to the decrease in the concentration of free preformed amino-phenolate ions [32].

The obtained results are compared with other metalbased catalysts reported in the literature for hydrogenation reduction of $p$-nitrophenol using the activity factor $(K)$, which is defined as the values of pseudo-first order rate constants $(\mathrm{k})$ per gram of the catalyst used. Based on the data listed in Table 2, it is clear that our synthesized CA3 nanocrystals shows high catalytic performance compared to noble metal $\mathrm{Au}-\mathrm{Fe}_{3} \mathrm{O}_{4}$ nanocatalyst, $\mathrm{Cu} 18 \mathrm{Ag}$ alloy nanoparticles andCuO@ $\mathrm{Ag}^{0}$ nanocatalysts. Even though, the catalytic activity factor is less compared to the previously reported $\mathrm{Cu} / \mathrm{CuO}$-Ag nanocatalyst, our new catalyst is superior in terms of low synthesis time.

The conversion of $p$-nitrophenol to $p$-aminophenol is thermodynamically favorable because of the suitable electrode potential of $\mathrm{NaBO}_{2} / \mathrm{NaBH}_{4}(-1.33 \mathrm{~V})$ and 4-NP/4-AP $(-0.76 \mathrm{~V})$ under normal hydrogen electrode [36]. However, the reaction is not feasible under normal conditions due to the large kinetic barrier between the nitrophenolate and
$\mathrm{BH}_{4}{ }^{-}$species $[23,37] . p$-nitrophenol gets deprotonated to nitrophenolate ions in the presence of $\mathrm{NaBH}_{4}$. The important step in the catalytic hydrogenation of $p$-nitrophenol to $p$-aminophenol is the adsorption-desorption mechanism. The reaction commences with the adsorption of nitrophenolate and borohydride ions on the active sites of the catalyst. Then the electron transfer from the $\mathrm{BH}_{4}{ }^{-}$to nitrophenolate ions through the catalyst interface results in the reduction products. The desorption and diffusion of the hydrogenated products from the catalyst surface follows [38]. The $p$-nitrophenol reduction follows pseudofirst order reaction kinetics [39].

The higher catalytic rate constant of $\mathrm{Cu}-\mathrm{CuO}$ compared to commercial copper powder can be due to the presence of intimate contact between the metal and metal oxide nanostructures. Reports suggest that the presence of such an interaction will always facilitate the transfer of electrons from metal to metal oxide. This occurs due to the variation in the Fermi level alignment resulting in the charge redistribution [20]. The enhancement in the catalytic reduction rate of $\mathrm{Cu}-\mathrm{CuO}-\mathrm{Ag}$ over $\mathrm{Cu}-\mathrm{CuO}$ nanocomposite can be due to a combination of several reasons. In the $\mathrm{Cu}-\mathrm{CuO}-\mathrm{Ag}$ nanocomposite, $\mathrm{Cu}-\mathrm{CuO}, \mathrm{Cu}-\mathrm{Ag}$ and $\mathrm{Ag}-\mathrm{CuO}$ interfaces are present. Then using such a nanocomposite as catalysts always offers a chance of transfer of electrons and hydride ions from $\mathrm{Cu}$ or $\mathrm{Ag}$ surface to the $\mathrm{CuO}$ surface. Such a charge distribution results in an electron rich region around $\mathrm{CuO}$ and electron free region around $\mathrm{Ag}$ or Cu leading to the formation of a depletion layer. The presence of surplus electrons over the $\mathrm{CuO}$ surface will enhance the uptake of electrons by nitrophenolate ions by effectively increasing the depletion area and thus enhancing catalytic activity [23].

Besides, the high electrical conductivity of silver $\left(6.30 \times 10^{7} \mathrm{Sm}^{-1}\right)$ also favors the adsorption of the reactant species and electrons. The higher catalytic activity of $\mathrm{Cu}-\mathrm{CuO}-\mathrm{Ag}$ nanocomposite also suggests the fast desorption of $p$-aminophenol from the catalyst surface. This can be attributed to the repulsion forces arising due to the increase in proton concentration around the catalyst surface [40]. Among the $\mathrm{Cu}-\mathrm{CuO}-\mathrm{Ag}$ nanocomposite, the
Table 2 Comparison between catalytic activities with previous reports

\begin{tabular}{lllll}
\hline Samples & Quality/mg & $\begin{array}{l}\text { Rate constant } \\
(\mathrm{k}) / \mathrm{s}^{-1}\end{array}$ & $\begin{array}{l}\text { Activity factor } \\
(\mathrm{K}) / \mathrm{s}^{-1} \mathrm{mg}^{-1}\end{array}$ & Reference \\
\hline $\mathrm{Cu}_{18} \mathrm{Ag}$ alloy nanoparticles & 2 & 0.00395 & 0.0019 & {$[10]$} \\
${\mathrm{CuO} @ \mathrm{Ag}^{0}}_{\mathrm{Flower-like} \mathrm{Au}-\mathrm{Fe}_{3} \mathrm{O}_{4}}^{\mathrm{NA}}$ & 2 & 0.004 & $\mathrm{NA}$ & {$[33]$} \\
Dumbbell-like $\mathrm{Au}-\mathrm{Fe}_{3} \mathrm{O}_{4}$ & 2 & 0.0063 & 0.0003 & {$[34]$} \\
$\mathrm{CuO}$ & 5 & 0.0105 & 0.0001 & {$[34]$} \\
$\mathrm{Cu} / \mathrm{CuO}-\mathrm{Ag}$ & 1.5 & 0.00237 & 0.00047 & {$[35]$} \\
$\mathrm{CA} 3$ nanocrystals & 7.5 & 0.046 & 0.0306 & {$[23]$} \\
\hline
\end{tabular}


variation in catalytic activity might be due to the differences in the synergistic effects of different parameters including structure effects, composite effects, and size effects $[32,41]$. The catalytic performance of any catalytic system greatly depends on the atomic distribution and ratio of the constituents since even a slight alternation in the local electron density influences the catalytic activity. The enhanced catalytic activity of CA3 nanocatalyst can be attributed to the depleted layer and enhanced electron density regions created by the synergistic action of $\mathrm{Cu}$, $\mathrm{CuO}$ and $\mathrm{Ag}$ interfaces. In turn this allows the CA3 nanocatalyst to facilitate the interaction between maximum number of nitrophenolate ions and catalytically active sites [42]. A decrease in the catalytic activity is observed when the copper content increases further as in CA4. The increase in copper content consequentially decreases the instances of favorable interfaces and disrupt the synergistic behavior observed in CA3 [43]. The catalytic enhancement depends on the proportion of $\mathrm{Cu}$ and $\mathrm{Ag}$ in the nanocomposites.

\section{Conclusion}

In summary, we have developed a facile method for the synthesis of $\mathrm{Cu}-\mathrm{CuO}-\mathrm{Ag}$ nanocomposite using a lowcost approach. The catalytic activity of the synthesized $\mathrm{Cu}-\mathrm{CuO}-\mathrm{Ag}$ nanocomposite was investigated in the catalytic reduction of $p$-nitrophenol to $p$-aminophenol. The results reveal that $\mathrm{Cu}-\mathrm{CuO}-\mathrm{Ag}$ composite nanoparticles possess higher catalytic activity than $\mathrm{Cu}-\mathrm{CuO}$ nanocomposite and commercial copper. Among the $\mathrm{Cu}-\mathrm{CuO}-\mathrm{Ag}$ nanocomposite, the $\mathrm{CA} 3$ composite, synthesized using the copper to silver precursor ratio of 16:1 exhibited enhanced catalytic activity. The maximum rate was observed for the catalyst amount of $10 \mathrm{mg}$. The enhanced catalytic performance of $\mathrm{Cu}-\mathrm{CuO}-\mathrm{Ag}$ nanocomposite arise from the synergistic effect of $\mathrm{Cu}-\mathrm{CuO}-\mathrm{Ag}$ interfaces. An optimal amount of copper to silver ratio was observed where this synergism was maximized. Our facile synthetic method could be extended for the synthesis of other copper-based nanostructures, such as the $\mathrm{Cu} / \mathrm{Au}$ and $\mathrm{Cu} / \mathrm{Pt}$ bimetallic nanoparticles. The low cost, easily scalable preparation presented and insights into enhancing the catalytic activity will be useful in designing efficient catalysts for degradation of organic pollutants.

Acknowledgements RK and BKV acknowledge the funding from KSCSTE project (Order No.1562/2016/KSCSTE) and UGC start-up Grant No. F 30-384/2017 (BSR) We also acknowledge Kannur University for providing the Grant by minor research project (PI. D./A2/UGCMinor R. P/2018). The authors acknowledge the Nanomission project "SR/NM/NS-20/2014" for the XRD and SEM facility. The authors acknowledge the TEM Facility, funded by a TPF Nanomission, Gol project at Centre for Nano and Soft Matter Sciences,Bengaluru.

Compilance with ethical standards

Conflict of interest The author(s) declare that they have no competing interests

\section{References}

1. Bian J, Xiao M, Wang S, Wang X, Lu Y, Meng Y (2009) Highly effective synthesis of dimethyl carbonate from methanol and carbon dioxide using a novel copper-nickel/graphite bimetallic nanocomposite catalyst. Chem Eng J 147:287-296

2. Wang J, Chernavskii PA, Khodakov AY, Wang Y (2012) Structure and catalytic performance of alumina-supported copper-cobalt catalysts for carbon monoxide hydrogenation. J Catal 286:51-61

3. Mazumder V, Chi M, Mankin MN, Liu Y, O.n. Metin, D. Sun, K.L. More, S. Sun, (2012) A facile synthesis of MPd (M=Co, Cu) nanoparticles and their catalysis for formic acid oxidation. Nano Lett. 12:1102-1106

4. Devasenathipathy R, Liu Y-X, Yang C, Wang S-F (2017) Simple electrochemical growth of copper nanoparticles decorated silver nanoleaves for the sensitive determination of hydrogen peroxide in clinical lens cleaning solutions. Sens Actuat B Chem 252:862-869

5. Wu T, Xu T, Ma Z (2015) Sensitive electrochemical detection of copper ions based on the copper(II) ion assisted etching of Au@ Ag nanoparticles. Analyst 140:8041-8047

6. Stahrenberg K, Herrmann T, Wilmers K, Esser N, Richter W, Lee $M$ (2001) Optical properties of copper and silver in the energy range 2.5-9.0 eV. Phys Rev B 64:115111

7. Khan FU, Khan SB, Kamal T, Asiri AM, Khan IU, Akhtar K (2017) Novel combination of zero-valent Cu and Ag nanoparticles@ cellulose acetate nanocomposite for the reduction of 4-nitro phenol. Int J Biol Macromol 102:868-877

8. Muzikansky A, Nanikashvili P, Grinblat J, Zitoun D (2013) Ag dewetting in $\mathrm{Cu@Ag} \mathrm{monodisperse} \mathrm{core-shell} \mathrm{nanoparticles.}$ J Phys Chem C 117:3093-3100

9. Tsai C-H, Chen S-Y, Song J-M, Chen I-G, Lee H-Y (2013) Thermal stability of $\mathrm{Cu@Ag} \mathrm{core-shell} \mathrm{nanoparticles.} \mathrm{Corros} \mathrm{Sci}$ 74:123-129

10. Wu W, Lei M, Yang S, Zhou L, Liu L, Xiao X, Jiang C, Roy VA (2015) A one-pot route to the synthesis of alloyed $\mathrm{Cu} / \mathrm{Ag}$ bimetallic nanoparticles with different mass ratios for catalytic reduction of 4-nitrophenol. J Mater Chem A 3:3450-3455

11. Tsuji M, Hikino S, Tanabe R, Matsunaga M, Sano Y (2010) Syntheses of $\mathrm{Ag} / \mathrm{Cu}$ alloy and $\mathrm{Ag} / \mathrm{Cu}$ alloy core $\mathrm{Cu}$ shell nanoparticles using a polyol method. CrystEngComm 12:3900-3908

12. Chowdhury S, Bhethanabotla VR, Sen R (2009) Effect of Ag-Cu alloy nanoparticle composition on luminescence enhancement/ quenching. J Phys Chem C 113:13016-13022

13. Huang $X$, Li $Y$, Zhou H, Zhong $X$, Duan $X$, Huang $Y$ (2012) Simplifying the creation of dumbbell-like $\mathrm{Cu}-\mathrm{Ag}$ nanostructures and their enhanced catalytic activity. Chem Eur J 18:9505-9510

14. Zhang J, Yuan Y, Xu X, Wang X, Yang X (2011) Core/shell Cu@ Ag nanoparticle: a versatile platform for colorimetric visualization of inorganic anions. ACS Appl Mater Interfaces 3:4092-4100

15. Jeong S, Lee SH, Jo Y, Lee SS, Seo Y-H, Ahn BW, Kim G, Jang G-E, Park J-U, Ryu B-H (2013) Air-stable, surface-oxide free Cu nanoparticles for highly conductive $\mathrm{Cu}$ ink and their application to printed graphene transistors. J Mater Chem C 1:2704-2710 
16. Grouchko M, Kamyshny A, Magdassi S (2009) Formation of airstable copper-silver core-shell nanoparticles for inkjet printing. J Mater Chem 19:3057-3062

17. Wiberg GK, Mayrhofer KJ, Arenz M (2010) Investigation of the oxygen reduction activity on silver-a rotating disc electrode study. Fuel cells 10:575-581

18. Park Jl, Cheon J (2001) Synthesis of "solid solution" and "coreshell" type cobalt- platinum magnetic nanoparticles via transmetalation reactions. J Am Chem Soc 123:5743-5746

19. Ni X, Zhang J, Zhang Y, Zheng H (2007) Citrate-assisted synthesis of prickly nickel micro wiresand their surface modification with silver. J Colloid Interface Sci 307:554-558

20. Zhou N, Polavarapu L, Wang Q, Xu Q-H (2015) Mesoporous $\mathrm{SnO}_{2}$-coated metal nanoparticles with enhanced catalytic efficiency. ACS Appl Mater Interfaces 7:4844-4850

21. Oldfield G, Ung T, Mulvaney P (2000) Au@ $\mathrm{SnO}_{2}$ core-shell nanocapacitors. Adv Mater 12:1519-1522

22. Sasmal AK, Dutta S, Pal T (2016) A ternary $\mathrm{Cu}_{2} \mathrm{O}-\mathrm{Cu}-\mathrm{CuO}$ nanocomposite: a catalyst with activity. Dalton Trans 45:3139-3150

23. Liang Y, Chen Z, Yao W, Wang P, Yu S, Wang X (2017) Decorating of $\mathrm{Ag}$ and $\mathrm{CuO}$ on $\mathrm{Cu}$ nanoparticles for enhanced high catalytic activity to the degradation of organic pollutants. Langmuir 33:7606-7614

24. Xia X, Xie C, Cai S, Yang Z, Yang X (2006) Corrosion characteristics of copper microparticles and copper nanoparticles in distilled water. Corros Sci 48:3924-3932

25. Jin M, He G, Zhang H, Zeng J, Xie Z, Xia Y (2011) Shape-controlled synthesis of copper nocrystals in an aqueous solution with glucose as a reducing agent and hexadecylamine as a capping agent. Angew Chem Int Ed 50:10560-10564

26. Zhang S, Gao H, Li J, Huang Y, Alsaedi A, Hayat T, Xu X, Wang $X$ (2017) Rice husks as a sustainable silica source for hierarchical flower-like metal silicate architectures assembled into ultrathin nanosheets for adsorption and catalysis. J Hazard Mater 321:92-102

27. Dong Z, Le X, Dong C, Zhang W, Li X, Ma J (2015) Ni@ Pd coreshell nanoparticles modified fibrous silica nanospheres as highly efficient and recoverable catalyst for reduction of 4-nitrophenol and hydrodechlorination of 4-chlorophenol. Appl Catal B 162:372-380

28. Zhang J, Chen G, Guay D, Chaker M, Ma D (2014) Highly active PtAu alloy nanoparticle catalysts for the reduction of 4-nitrophenol. Nanoscale 6:2125-2130

29. Wang D, Zhao P, Li Y (2011) General preparation for Pt-based alloy nanoporous nanoparticles as potential nanocatalysts. Sci Rep 1:37

30. Sun Y, Zhang F, Xu L, Yin Z, Song X (2014) Roughness-controlled copper nanowires and Cu nanowires-Ag heterostructures: synthesis and their enhanced catalysis. J Mater Chem A 2:18583-18592

31. Pozun ZD, Rodenbusch SE, Keller E, Tran K, Tang W, Stevenson KJ, Henkelman G (2013) A systematic investigation of p-nitrophenol reduction by bimetallic dendrimer encapsulated nanoparticles. J Phys Chem C 117:7598-7604

32. Wei Z, Sun J, Li Y, Datye AK, Wang Y (2012) Bimetallic catalysts for hydrogen generation. Chem Soc Rev 41:7994-8008

33. Bouazizi N, Vieillard J, Thebault P, Desriac F, Clamens T, Bargougui R, Couvrat N, Thoumire O, Brun N, Ladam G, Morin S (2018) Silver nanoparticle embedded copper oxide as anefficient core-shell for the catalytic reduction of 4-nitrophenol and antibacterial activity improvement. Dalton Trans 47:9143-9155

34. Lin F-H, Doong R-A (2011) Bifunctional Au- $\mathrm{Fe}_{3} \mathrm{O}_{4}$ heterostructures for magnetically recyclable catalysis of nitrophenol reduction. J Phys Chem C 115:6591-6598

35. Yao W, Li F-L, Li H-X, Lang J-P (2015) Fabrication of hollow $\mathrm{Cu}_{2} \mathrm{O} @$ $\mathrm{CuO}$-supported $\mathrm{Au}-\mathrm{Pd}$ alloy nanoparticles with high catalytic activity through the galvanic replacement reaction. J Mater Chem A 3:4578-4585

36. Liang M, Wang L, Su R, Qi W, Wang M, Yu Y, He Z (2013) Synthesis of silver nanoparticles within cross-linked lysozyme crystals as recyclable catalysts for 4-nitrophenol reduction. Catal Sci Technol 3:1910-1914

37. Zhang P, Shao C, Zhang Z, Zhang M, Mu J, Guo Z, Liu Y (2011) In situ assembly of well-dispersed Ag nanoparticles (AgNPs) on electrospun carbon nanofibers (CNFs) for catalytic reduction of 4-nitrophenol. Nanoscale 3:3357-3363

38. Zhu D, Li X, Wang N, Wang X, Gao J, Li H (2009) Dispersion behavior and thermal conductivity characteristics of $\mathrm{Al}_{2} \mathrm{O}_{3}-\mathrm{H}_{2} \mathrm{O}$ nanofluids. Curr Appl Phys 9:131-139

39. Bouazizi N, Vieillard J, Thebault P, Desriac F, Clamens T, Bargougui R, Couvrat N, Thoumire O, Brun N, Ladam G (2018) Silver nanoparticle embedded copper oxide as an efficient core-shell for the catalytic reduction of 4-nitrophenol and antibacterial activity improvement. Dalton Trans 47:9143-9155

40. Boldyrev VV (2006) Thermal decomposition of ammonium perchlorate. Thermochim Acta 443:1-36

41. Xia B, He F, Li L (2013) Preparation of bimetallic nanoparticles using a facile green synthesis method and their application. Langmuir 29:4901-4907

42. Otari SV, Yadav HM, Thorat ND, Patil RM, Lee JK, Pawar SH (2016) Facile one pot synthesis of core shell Ag@ $\mathrm{SiO}_{2}$ nanoparticles for catalytic and antimicrobial activity. Mater Lett 167:179-182

43. Srisombat L, Nonkumwong J, Suwannarat K, Kuntalue B, Ananta $S$ (2017) Simple preparation Au/Pd core/shell nanoparticles for 4-nitrophenol reduction. Colloids Surf A Physicochem Eng Asp 512:17-25

Publisher's Note Springer Nature remains neutral with regard to jurisdictional claims in published maps and institutional affiliations. 